\title{
Non-Neoplastic Thoracic Disorder
}

National Cancer Institute

\section{Source}

National Cancer Institute. Non-Neoplastic Thoracic Disorder. NCI Thesaurus. Code C35743.

A non-neoplastic disorder that affects the thorax and/or the org ans of the thoracic cavity. Representative examples include pleural infection, mediastinitis, pneumonia, and chronic obstructive pulmonary disease. 